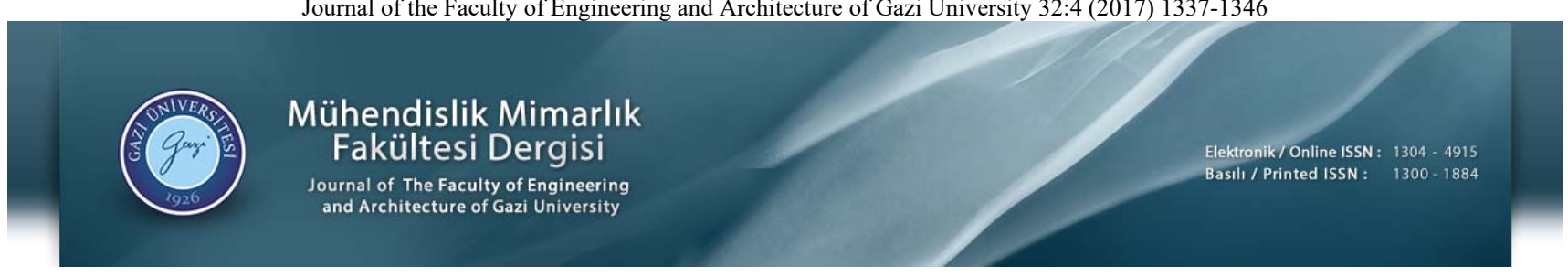

\title{
Transformatörlerin kazan duvarlarında meydana gelen kayıpların azaltılması için en uygun şönt eleman boyutlarının belirlenmesi
}

\author{
Mehmet Aytaç Çınar*(D), Bora Alboyacı² (D), Serenay Çürükova ${ }^{3}$ (D) Oluş Sönmez ${ }^{3}$ (D), Rauf Yapıc1 ${ }^{4}$ \\ ${ }^{1}$ Kocaeli Üniversitesi, İzmit Meslek Yüksekokulu, Arslanbey Yerleşkesi, 41285, Kartepe, Kocaeli, Türkiye \\ ${ }^{2}$ Kocaeli Üniversitesi, Elektrik Mühendisliği Bölümü, Umuttepe Yerleşkesi, 41380, İzmit, Kocaeli, Türkiye \\ ${ }^{3}$ Sönmez Transformatör San. ve Tic. A.Ş., Makine İhtisas Organize Sanayi Bölgesi, 41455, Dilovası, Kocaeli, Türkiye \\ ${ }^{4}$ GENETEK Enerji Ltd. Şti., KOU-Teknopark, 41090, Başiskele Kocaeli, Türkiye
}

Ö N E Ç I K A N L A R

- Transformatör kazan duvarlarında meydana gelen kayıpların belirlenmesi

- Kazan kayıplarının şönt elemanlar kullanılarak azaltılması

- En uygun şönt eleman boyutlarının belirlenmesi

Makale Bilgileri

Geliş: 03.09.2016

Kabul:30.01.2017

DOI:

10.17341/gazimmfd.369855

Anahtar Kelimeler:

Transformatör,

kazan kayıpları,

şönt eleman,

boyutlandırma,

kayip azaltma

\section{ÖZET}

Yağlı tip transformatörlerdeki kazan ve diğer metal yapısal elemanlar üzerinde meydana gelen güç kayıpları, toplam kayıpların azaltılmasına yönelik olarak gerçekleştirilen çalışmalarda göz önünde tutulması gereken etkenlerden biridir. Bu kayıplar sargıların çevresindeki kaçak akılar sebebiyle transformatörün yapısal metal parçaları üzerinde oluşmakta ve bu parçalarda aşırı ısınmaya yol açmaktadır. Bu çalışmada, kazan duvarları üzerinde meydana gelen bu kayıpları azaltmak amacıyla kazan duvarlarının iç yüzeyine yerleştirilen şönt elemanların en uygun boyutlarının belirlenmesi amaçlanmaktadır. Bu doğrultuda özel olarak tasarlanan bir transformatör için sonlu elemanlar yöntemi kullanılarak elektromanyetik analizler gerçekleştirilmiş olup, analiz sonuçları deneysel çalışmalar ile doğrulanmıştır. Elde edilen sonuçlar ile kazan duvarlarının iç yüzeyine yerleştirilecek en uygun şönt boyutları transformatörün sargı boyutlarına bağlı olarak ifade edilmektedir. Belirlenen boyutlardaki şönt elemanların kullanımı ile kazan duvarlarında meydana gelen kayıpların \%91,43, toplam kısa devre kayıplarının ise \%14,9 oranında azaltılması mümkün olmuştur.

\section{Calculation of optimum dimensions of magnetic shunt elements to reduce stray losses on transformer tank walls}

\section{H I G H L I G H T S}

- Determining stray losses in transformer tank walls

- Reducing stray losses using magnetic shunt elements

- Calculating optimum shunt dimensions

Article Info

Received: 03.09.2016

Accepted: 30.01 .2017

DOI:

10.17341/gazimmfd.369855

Keywords:

Transformer,

stray losses,

magnetic shunts,

optimum dimensions, loss

reduction

\section{ABSTRACT}

Stray losses should be carefully considered in loss reduction studies, to increase efficiency of oil immersed transformers. These losses occur due to leakage fluxes and cause local hot-spots and overheating on the tank walls and other structural metal parts. In this study, obtaining an expression of suitable shunt dimensions which satisfactorily reduces the stray losses on tank walls, is aimed. 3D finite element method was intensively used in analyses and main results were also validated by experimental studies. A simple expression of shunt dimensions is proposed. To generalize this expression, obtained shunt dimensions are expressed by means of winding dimensions. Using this optimum shunt dimensions, tank wall losses and total short circuit losses were reduced by $91.43 \%$ and $14.9 \%$, respectively.

\footnotetext{
*Sorumlu Yazar/Corresponding Author: aytac@kocaeli.edu.tr/ Tel: +90 2623513286
} 


\section{GIRIŞS (INTRODUCTION)}

Transformatörler enerji dağıtım şebekesinde büyük rol üstlenen fakat önemli ölçüde kayıplara neden olan elemanlardır. 1 Temmuz 2015 tarihinden itibaren yürürlüğe girmiş olan EN 50588-1 standardı ile dağıtım transformatörlerinde meydana gelen güç kayıplarının sınır değerleri yeniden düzenlenmiş̧tir [1]. Güç kayıplarını bu standardın gerektirdiği düzeye indirebilmek için, transformatörde kayıplara neden olan tüm faktörlerin dikkatle göz önünde tutularak iyileştirilmesi gerekmektedir. Transformatörlerde meydana gelen toplam güç kayıpları, boşta çalışma ve yüklü çalışma kayıplarının toplamı biçiminde ifade edilmektedir. Boşta çalışma kayıplarının aksine yüklü çalışma kayıpları, transformatörün sargılarından akan yük akımının karesi ile doğru orantılı olarak değişmektedir. $\mathrm{Bu}$ kayıplar; sarg1 iletkenlerinde meydana gelen sarg1 direnci kaynakl1 kayıplar, sarg1 iletkenlerinde eddy akımları nedeniyle oluşan kayıplar ve transformatörlerin devre tutucuları ve kazan duvarları gibi metal yapısal bileşenlerinde oluşan kayıplardan meydana gelmektedir [2]. Metal yapısal bileşenlerdeki bu kayıplar transformatördeki kaçak akı nedeniyle meydana gelmekte olup sargı yapısı, yapısal bileşenler ile sargılar arasındaki uzaklık, yapısal bileşenlerin imal edildiği metal malzemenin elektromanyetik özellikleri gibi birçok parametreye bağlıdır. Bu kayıplar yapısal bileşenler üzerinde yüksek sıcaklıklar meydana getirmekte ve zaman zaman transformatörün işletme dışı kalmasına sebep olmaktadır. Özellikle kazan duvarları üzerinde meydana gelen güç kayıplarının miktarı üzerinde transformatör sargılarının yerleşiminin etkisi olduğu görülmektedir [3]. Literatürde, transformatörün kazan ve diğer yapısal bileşenlerindeki kayıpların belirlenmesi ve azaltılmasına ilişkin çalışmalar bulunmaktadır. $\mathrm{Bu}$ amaçla sonlu elemanlar yönteminin kullanımı tasarım ve iyileştirme aşamasında avantaj sağlamaktadır [4]. Transformatör kazanının yanı sıra [5] diğer bileşenlerin geometrik tasarımlarından dolayı, bu elemanlar üzerindeki kayıplar özellikle üç boyutlu analizler ile yüksek doğrulukla hesaplanabilmektedir [6]. Ayrıca, yapısal bileşenlerin imal edildiği metal malzemenin elektriksel iletkenliği ve manyetik geçirgenliği gibi elektromanyetik parametrelerinin de bu bileşenler üzerinde meydana gelen kayıpları önemli düzeyde etkilemesi sebebiyle sonlu elemanlar yöntemi kolaylık sağlamaktadır [7]. 40MVA gücündeki bir transformatörün kazan ve nüve tutucu elemanları üzerinde meydana gelen kayıplar üzerine gerçekleştirilmiş olan çalışma ile bu elemanların üretiminde kullanılan malzemenin geçirgenliğinin kayıplar üzerine olan etkisi gösterilmektedir [8]. Yapısal bileşenlerdeki toplam kayıpların büyük kısmının kazan üzerinde meydana gelmesi sebebiyle, literatürdeki mevcut çalışmaların çoğunda bu bileşenin incelendiği görülmektedir. Kazan duvarlarında meydana gelen kayıpların azaltılması amaciyla manyetik olmayan malzemeler kullanılarak ekranlama yapılması veya yine manyetik olmayan malzemelerden imal edilen şönt elemanların kullanılması yöntemleri yaygın olarak uygulanmaktadır. Bununla birlikte, gerçekleştirilen çalışmaların çok büyük kısmı güç transformatörleri 1338 odaklıdır. Dağıtım transformatörleri üzerine gerçekleştirilen sınırlı sayıdaki çalışmalardan birinde, 50kVA gücündeki bir transformatör incelenmektedir. Burada kazan duvarlarının iç yüzeyine alüminyum malzeme kullanılarak gerçekleştirilen ekranlama uygulaması ile kazan kayıplarında \%50 oranında azalma sağlandığı ifade edilmektedir [9]. Bir bașka çalışmada ise $500 \mathrm{kVA}$ gücünde bir transformatör için gerçekleştirilen farklı kalınlıklardaki alüminyum ekranlamanın kazan kayıpları üzerine olan etkisi maliyet yönüyle de incelenmiş olup, uygulamanın küçük güç düzeyleri için ekonomik olmadığı sonucunda varılmaktadır. $[10,11]$ 'de ise kazan duvarında meydana gelen kayıpların azaltılmasında şönt eleman ve alüminyum ekranlama uygulaması incelenmekte olup, özellikle bölgesel kayıpların azaltılmasında şönt eleman uygulamasının avantajlı olduğu ifade edilmektedir. Bir başka çalışmada ise, 82MVA gücündeki bir güç transformatörünün yüksek akım sargılarının buşing bağlantı iletkenlerinin kazan duvarları üzerinde meydana getirdiği bölgesel 1sınmanın azaltılması için alüminyum levhalar ile şönt uygulaması yapılmakta olup uygulamanın etkinliği ve sicaklığın \%43,3 oranında azaltıldığı ifade edilmektedir [12]. Transformatör üzerinde kayıpların meydana geldiği diğer yapısal parçalara yönelik olarak da azaltıcı yönde önlemler alındığı görülmektedir. Bu parçalardan biri olan nüve tutucu elemanlarda meydana gelen kayıplar uygun boyut ve şekilde alüminyum malzeme kullanılarak azaltılmaktadır [13]. Özellikle büyük güçlü transformatörlerde, kaçak akının nüve tutucular üzerinde meydana getirdiği kayıplar, sargılar ile nüve tutucular arasına yerleştirilen manyetik şönt elemanlar ile engellenebilmektedir [14]. Kazan üzerinde ise alçak gerilim iletkenlerinin bağlantı bölgelerinin manyetik olmayan malzemeden imal edilmesi ile bu kısımlardaki kayıpların ve bölgesel olarak meydana gelen yüksek sıcaklığın azaltılması sağlanmaktadır [15].

Bu çalışmada, kazan duvarlarında meydana gelen kayıpların azaltılması amaciyla şönt eleman kullanılması yöntemi incelenmektedir. Tasarım aşamasında transformatördeki kayıpların azaltılması ve uygun şönt eleman boyutlarının belirlenmesi amacıyla elektromanyetik analiz çalışmalarının gerçekleştirilmesi gerekmektedir. Bu sürecin uzun zaman alması sebebiyle transformatör üreticileri kullanılacak şönt elemanların boyutlarını önceki uygulamalarından elde edilen tecrübeler ile tahmini olarak öngörmektedir. Bu şekilde elde edilen sonuçlar çoğu zaman elde edilebilecek en uygun durumdan çok uzak kalmaktadır. Bu çalışma ile şönt elemanların kazan kayıplarının tatmin edici düzeyde azaltılmasını sağlayacak en uygun boyutlarının belirlenmesi ve elde edilen sonucun transformatörlerde kazan kayıplarını azaltmaya yönelik olarak genelleştirilerek ifade edilmesi hedeflenmektedir. Çalışmada yoğun şekilde üç boyutlu sonlu elemanlar analizleri gerçekleştirilmiş olup, önem taşıyan bazı analizlere ait sonuçlar deneysel çalışmalar ile doğrulanmıştır. $\mathrm{Bu}$ doğrultuda, ilk olarak transformatör kazanının boyutlarının kazan üzerinde meydana gelen kayıplar üzerine etkisi incelenmiş olup, boyutlardaki değişikliğin kazan kayıpları üzerine olan olumlu ve olumsuz etkileri değerlendirilmiştir. Ardından şönt elemanların 
kullanımı ve boyutlandırmasına ilişkin çalışmalar ve değerlendirmeler gerçekleştirilmiştir. Belirlenen en uygun şönt eleman boyutları kazan kayıplarını transformatördeki kaçak akının meydana getirmesi sebebiyle sargı boyutlarına bağlı olarak öngörülerek ifade edilmektedir. Böylelikle elde edilen sonuçların farklı transformatörler için de uygulanabilir olması sağlanması hedeflenmiştir.

\section{2. İNCELENEN TRANSFORMATÖR (STUDIED TRANSFORMER)}

Güç transformatörlerinin yapısal bileşenlerinde meydana gelen kayıplar, transformatörün yüklü çalışması durumunda meydana gelen toplam kayıların \%20-50'si düzeyindedir [16]. $\mathrm{Bu}$ nedenle literatürde bu kayıplar üzerine gerçekleştirilen çalışmaların neredeyse tamamının güç transformatörleri üzerine odaklandığı görülmektedir. Buna karşın ilgili uluslararası düzenlemelerde belirtilen sınıflandırmaların gerektirdiği kayıp güç sınırları, yapısal elemanlar üzerinde meydana gelen kayıpların standart ve özel tip dağıtım transformatörleri için de değerlendirilmesi ve azaltılması gerektiğini ortaya koymaktadır.

$\mathrm{Bu}$ çalışmanın amacı doğrultusunda kazan üzerinde meydana gelen kayıları azaltmak amacıyla uygulanacak yöntemlerin etkinliğinin belirlenmesinde deneysel çalışmalar önem taşımaktadır. Prototip bir güç transformatörünün ve gerekli şönt elemanların üretimi zaman almakta ve maliyeti oldukça yüksek olmaktadır. Standart bir dağıtım transformatöründe ise bu kayıpların düşük seviyede olması sebebiyle, deneysel aşamada kullanılacak şönt eleman boyutlarındaki değişimlerin bu kayıplar üzerine olan etkilerinin hassas biçimde ölçülmesi ve yorumlanması zorluklar içermektedir. $\mathrm{Bu}$ sebeplerle, bu çalışmada kazan üzerinde meydana gelen kayıpların ve kullanılacak farklı boyutlardaki şönt elemanların etkinliğinin belirlenmesi amacıyla özel olarak tasarlanmış bir dağıtım transformatörü kullanılmaktadır. $\mathrm{Bu}$ amaçla üretilen transformatör üç fazlı, 1000kVA gücünde, $34,5 / 0,4 \mathrm{kV}$ gerilim seviyesinde bir dağıtım transformatörü olup, bağıl kısa devre gerilimi \%16,5 olacak şekilde tasarlanmıştır. Transformatörün nüvesi M5 malzeme kullanılarak, sargılar ise bakır iletken kullanılarak üretilmiștir. Tasarlanan transformatör ve diğer yapısal bileşenlerine ilişkin boyutlar Tablo 1'de verilmektedir. Üretilen prototip transformatörün fotoğrafi Şekil 1'de; transformatörün nüve, sargilar, devre tutucular ve kazan duvarlarının da belirtildiği üç yönden gösterilen modeli ise Şekil 2'de görülmektedir.

Tablo 1. Prototip transformatörün temel boyutları (Main dimensions of prototype transformer)

\begin{tabular}{ll}
\hline Sargı boyutları, mm & \\
\hline Yüksek gerilim sargısı ortalama çapı & $: 530$ \\
Alçak gerilim sargısı ortalama çapı & $: 256$ \\
Yükseklik & $: 690$ \\
\hline Kazan boyutları, mm & $: 1900 / 690 / 1340$ \\
\hline Uzunluk / Derinlik / Yükseklik & $: 5$ \\
Yan duvarların kalınlığı & $: 6$ \\
Üst kapak ve alt taban kalınlığı &
\end{tabular}

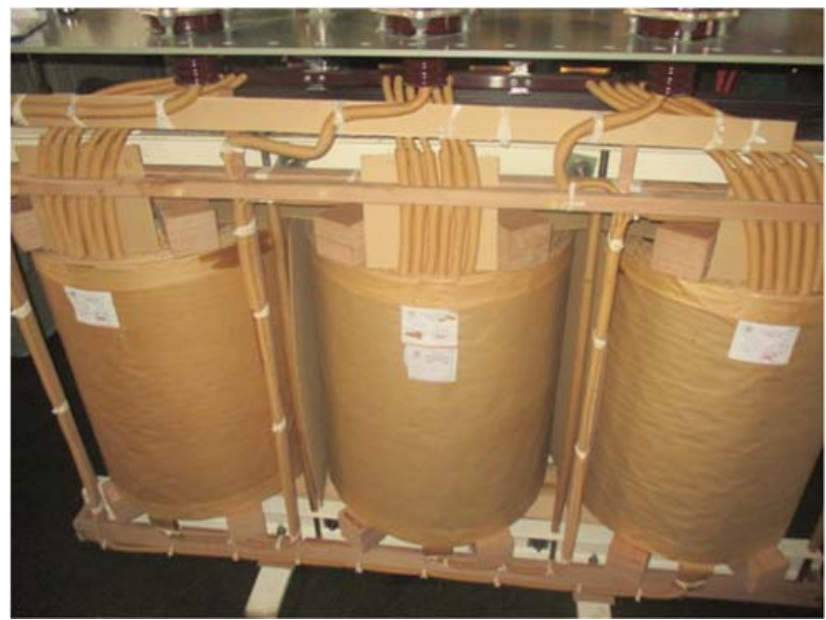

Şekil 1. Üretilen prototip transformatörün aktif kısımları (Active parts of manufactured prototype transformer)

\section{PROTOTIP TRANSFORMATÖRDE GÜÇ KAYIPLARI (POWER LOSSES OF STUDIED TRANSFORMER)}

Prototip transformatördeki kayıpların doğru biçimde belirlenmesi, bu kayıpların azaltılması için uygulanacak olan yöntemlerin verimliliğinin belirlenmesi için referans oluşturacağından dolayı büyük önem taşımaktadır. Kazan duvarları ve nüve tutucu elemanların imalatında kullanılan malzemelerin elektromanyetik özellikleri sebebiyle, bu elemanların üzerinde meydana gelen kayıpların belirlenmesi amaciyla sonlu elemanlar yöntemi kullanılarak elektromanyetik analizler gerçekleştirilmiştir. Bu amaçla ANSYS Maxwell v16 yazılımından yararlanılmıştır.

Transformatör modelinin zaman domeninde analizi için tanımlanan üç boyutlu elektromanyetik problemin çözümünde kullanılacak ifadeler Eş. 1, Eş. 2 ve Eş. 3'te verildiği biçimde sıralanmaktadır.

$\overrightarrow{\mathrm{B}}=\nabla \times \overrightarrow{\mathrm{A}}$

$\nabla \times \overrightarrow{\mathrm{E}}=-\frac{\partial \overrightarrow{\mathrm{B}}}{\partial \mathrm{t}}$

$\nabla \times \frac{1}{\mu}(\nabla \times \overrightarrow{\mathrm{A}})=\overrightarrow{\mathrm{J}}-\sigma \frac{\partial \overrightarrow{\mathrm{A}}}{\partial \mathrm{t}}$

Bu eşitliklerde; H manyetik alan şiddeti, J akım yoğunluğu, $\mu$ geçirgenlik, $\sigma$ elektriksel iletkenlik, E elektrik alan şiddeti, B manyetik akı yoğunluğu ve A manyetik vektör potensiyelini ifade etmektedir.

ANSYS Maxwell v16 yazılımı üç boyutlu statik ve dinamik manyetik analiz problemlerinde manyetik alan $(\mathrm{H})$ ve akım yoğunluğu (J) büyüklüklerinin çözümünü gerçekleştirmekte ve manyetik akı yoğunluğu (B) değeri manyetik alan büyüklüğünden yola çıkılarak türetilmektedir. Yazılım modelin karmaşıklığını azaltmak amacıyla sınır koşullarını otomatik olarak belirlemektedir [17]. Problemde analizi gerçekleştirilen transformatör 1:1 ölçekte tam model olarak 


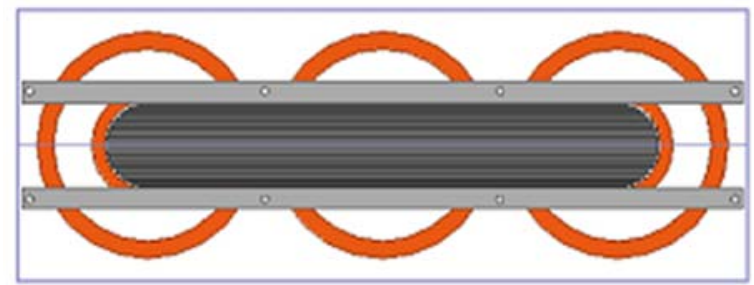

(a)

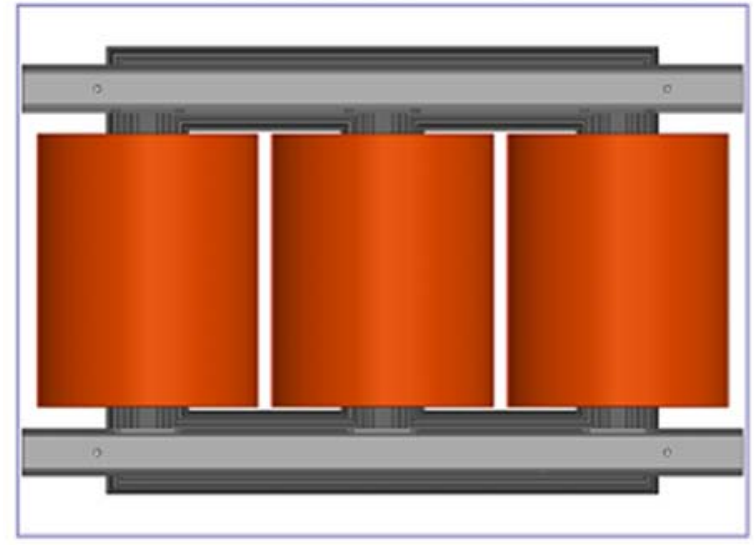

(b)

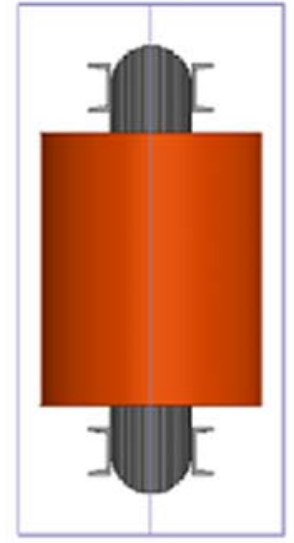

(c)

Şekil 2. Prototip transformatör modelinin a) üstten b) önden c) yandan görünüşü ( a) Top b) front c) side view of prototype transformer model)

modellenmiştir. Transformatörü çevreleyen uygun boyutta bir sonlu hacim tanımlanarak, çözüm bu hacmin içerisinde gerçekleştirilmiştir. Bu hacmin dış yüzeylerinde Neumann sınır koşulları uygulanmıştır. Problemin çözümünde transformatörün kısa devre çalışma durumu analiz edilerek, meydana gelen kaçak akı ve bunun sonucunda oluşan kayıp bileşenlerinin büyüklükleri belirlenmiştir. Kaçak akının özellikle kazan duvarları üzerinde etki edeceği yüzey derinliği, kazan duvarlarının elektromanyetik değerlerine bağlı olup Eş. 4 ile hesaplanmaktadır.

$$
\delta=\sqrt{\frac{2}{\omega \mu_{0} \mu_{\mathrm{r}} \sigma}}
$$

Burada $\mu_{\mathrm{r}}$ kazanın imalatında kullanılan malzemenin bağıl manyetik geçirgenliği, $\mu_{0}$ ise boşluğun manyetik geçirgenlik değeri, $\sigma$ elektriksel iletkenlik, $\omega$ ise açısal frekanstır. Bu yüzey derinliğinin çok küçük olması, elektromanyetik analizler esnasında oluşturulacak sonlu elemanların boyutlarının çok küçük ve sayısının ise fazla olmasına neden olarak, gerekli çözüm süresinin ve ihtiyaç duyulan işlemci gücünün artmasını gerektirmektedir. Bu nedenle benzetim çalışmalarında kazan duvarları için literatürde de üstünlüğü belirtilen yüzey empedans yöntemi kullanılmıştır [18]. Böylelikle modelin bütününde ihtiyaç duyulan sonlu eleman sayısının ve çözüm süresinin azalması sağlanmıştır. Benzetim çalışmalarında oluşturulan üç boyutlu modellerin her birinde ortalama olarak 270000 adet sonlu elemandan oluşan ağ yapısı tanımlanmıştır. Meydana gelen kayıpların miktarı Eş. 5 kullanılarak hesaplanmaktadır.

$$
\mathrm{P}=\iint_{\mathrm{S}} \sqrt{\frac{\omega \mu}{2 \sigma}} \frac{\mu_{0}^{2}}{2} \mathrm{ds}
$$

Transformatör sargılarının modellenmesinde elektriksel iletkenliği $\sigma=5,8.10^{7} \mathrm{~S} / \mathrm{m}$ ve bağıl manyetik geçirgenliği $\mu_{\mathrm{r}}=1$ olan bakır malzeme, nüve tutucu ve kazan duvarlarında ise elektriksel iletkenliği $\sigma=5.10^{6} \mathrm{~S} / \mathrm{m}$ ve bağıl manyetik geçirgenliği $\mu_{\mathrm{r}}=500$ olan düşük karbonlu çelik malzeme kullanılmıştır. Benzetim çalışmalarının ve elde edilen analiz sonuçlarının doğrulanması amaciyla, prototip transformatörün kısa devre testi laboratuvar ortamında gerçekleştirilmiştir. Çalışmanın genelinde uygulanan tüm k1sa devre testleri EN60076-1 standardı gerekliliklerine uygun şekilde ve anma akımı ile gerçekleştirilmiştir. Akım, gerilim ve güç ölçümleri ise transformatörün primer tarafindan a-eberle PQ-Box 150 Mobil Enerji Analizörü kullanılarak alınmaktadır. Transformatörün yapısal bileşenlerinde meydana gelen kayıların ayrı ayrı belirlenmesi, benzetim çalışmasının aksine deneysel olarak kolaylıkla mümkün olamamaktadır. $\mathrm{Bu}$ amaçla, prototip transformatörün kısa devre testi kazan dışarısında ve kazan içerisinde olmak üzere iki kez tekrarlanmış olup, iki test arasında belirlenen kayıp güç farkı hesaplanarak kazan üzerinde meydana gelen kayıplar elde edilmiştir. Sonlu elemanlar analizi sayesinde ise kazanın yan duvarları, üst kapak ve taban üzerinde meydana gelen kayıpların ayrı ayrı belirlenmesi mümkün olmuştur. Kazan yan duvarları üzerinde ak1 yığılmaları gözlenmekte olup bunun sonucunda meydana gelen güç kayıplarının dağılımı Şekil 3'te gösterilmektedir. 


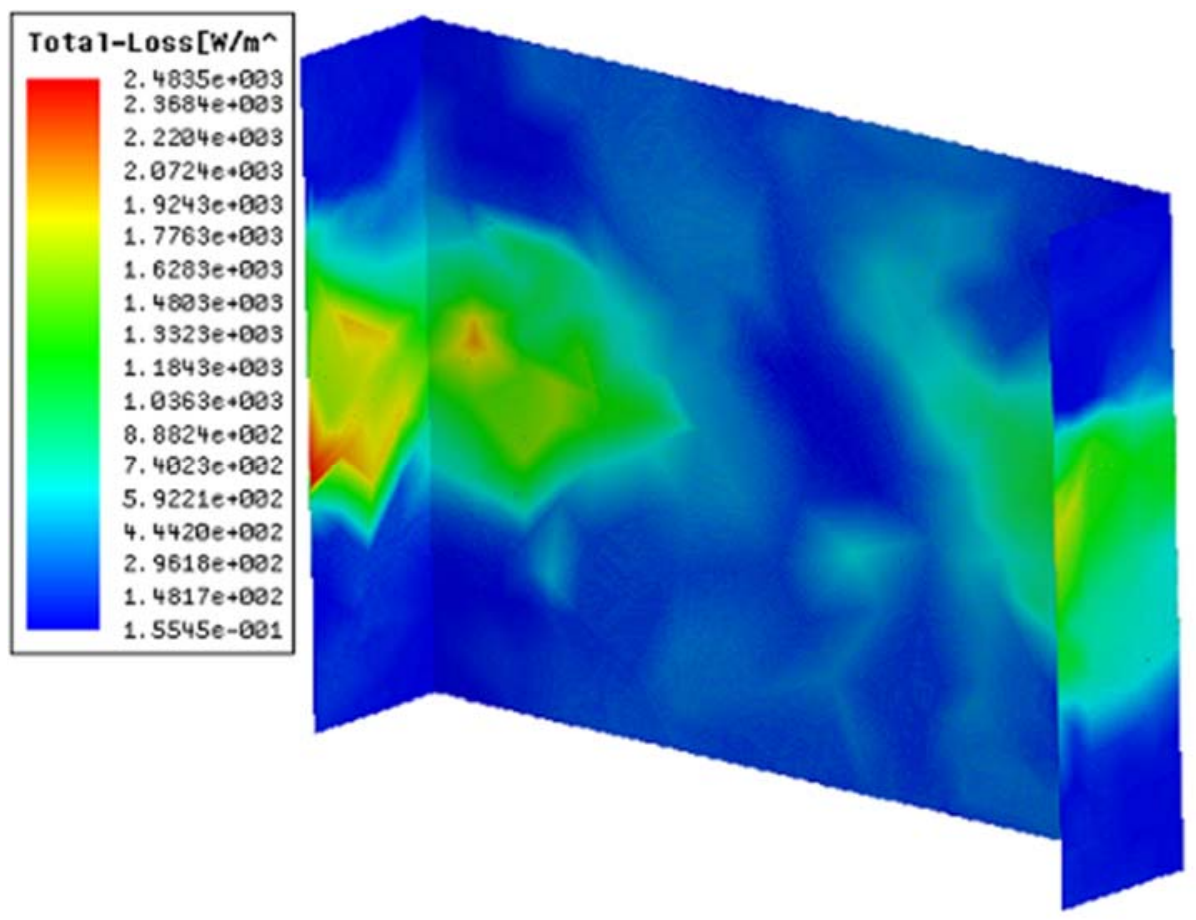

Şekil 3. Kazan duvarlarının iç yüzeyinde gözlenen güç kayıplarının dağılımı (Loss distribution on the inner surface of tank wall)

\section{KAZAN DUVARLARINDAKİ KAYIPLARIN ANALİŻ (TANK LOSS ANALYSES)}

Kazan duvarlarında meydana gelen kayıpların başlıca sebebi, sargılardan akan akımın yarattığı manyetik alandan kaynaklanan ve kazan duvarlarına sirayet eden kaçak akılardır. Bu nedenle, sargılar ile kazan duvarları arasındaki uzaklık, meydana gelen kayıpları etkilemektedir. Bu uzakıı̆ıı artırılması ile kazan kayıplarının azaltılması mümkün olmakla beraber, kazan boyutlarındaki artış kazan hacmini ve ihtiyaç duyulacak yağ miktarını da artıracağından transformatörün toplam ağırlığı ve maliyetinde de artışa neden olmaktadır. Bu sebeplerden dolayı, kazan kayıplarının azaltılması amacı doğrultusunda kazan boyutlarının artırılmasının ne kadar etkili sonuçlar meydana getireceğinin belirlenmesi gerekmektedir. Bu amaçla, geliştirilen prototip transformatörün kazan duvarlarında meydana gelen kayıpların kazan boyutlarına bağlı değişimi, sonlu elemanlar yöntemi kullanılarak gerçekleştirilen elektromanyetik analizler ile belirlenmiştir.

Benzetim çalışmalarının sonucunda görüldüğü üzere, kazanda meydana gelen güç kayıplarının \%92,8’i kazanın yan duvarlarında meydana gelmektedir. Bu nedenle, kazanın üst kapak ve alt tabanındaki kayıplar ihmal edilerek sadece yan duvarlarda meydana gelen kayılar göz önünde tutulmaktadır. Orijinal kazan tasarımında yüksek gerilim sargıları ile kazan duvarı arasındaki uzaklık 50mm olarak belirlenmiştir. Bu uzaklık, uzun ve kısa yan duvarların her biri için 50mm'lik adımlar ile 250mm'ye kadar sırasıyla artırılarak benzetim çalışmaları tekrarlanmış ve kazan duvarları üzerinde meydana gelen kayıplardaki değişim belirlenmiştir. İlk olarak, kısa yan duvarın uzunluğu sabit tutularak orijinal kazan tasarımında $1900 \mathrm{~mm}$ olan uzun yan duvarın uzunluğu 100mm'lik adımlar ile 2400mm'ye kadar artırılmıştır. Ardından uzun yan duvarın uzunluğu orijinal tasarım değerinde sabit tutularak, orijinal kazan tasarımında $690 \mathrm{~mm}$ olan kısa yan duvarın uzunluğu $100 \mathrm{~mm}$ 'lik adımla ile $1190 \mathrm{~mm}$ 'ye kadar artırılmıştır. Her iki durumda kazan kayıplarının değişimi belirlenmiş olup Şekil 4 ve Şekil 5 'te verilmektedir. Elde edilen sonuçlar, kazan duvarlarında meydana gelen kayıların kazan duvarı ile sargılar arası uzaklık ile ters orantılı olarak değiştiğini göstermektedir. Yüzey alanına bağlı olarak, kazan kayıplarının büyük kısmı uzun yan duvarlar üzerinde meydana gelmektedir. Kazanın uzun yan duvarları ile sargılar arasındaki uzaklık $300 \mathrm{~mm}$, kısa yan duvarları ile en yakın sargı arasındaki uzaklığın 500mm olduğu durumda toplam kazan kaybı 1897,74W olarak hesaplanmaktadır. Kazanın uzun yan duvarları ile sargılar arası uzaklık 500mm, kısa yan duvarlar ile en yakın sarg1 arasındaki uzaklık $300 \mathrm{~mm}$ olduğu durumda ise toplam kazan kaybı 979,77W olarak hesaplanmaktadır. Bununla birlikte, orijinal tasarımda kazanın uzun yan duvarı ile sarg1 arasındaki uzaklığın her $100 \mathrm{~mm}$ 'lik artışı kazan hacminde $0,0925 \mathrm{~m}^{3}$ artışa ve dolaylı olarak $81,46 \mathrm{~kg}$ ilave yă gereksinimine neden olmaktadır. Benzer şekilde, kazanın k1sa yan duvarı ile sarg1 arasındaki uzaklığın her 100mm'lik artışı ise kazan hacminde $0,255 \mathrm{~m}^{3}$ artış ve $224,3 \mathrm{~kg}$ ilave yă ihtiyacı meydana getirmektedir. Bu değerler göz önünde tutularak, kazan boyutlarını artırarak kazan kayıplarının azaltılabileceği, buna karşın uygulamada yaratacağı ağırlık ve maliyet artışının uygulanabilirliği ortadan kaldıracağ sonucuna varılmaktadır. Bu sebeple, daha büyük kazan boyutları öngörülerek ilave analizlere gerek duyulmamıştır. 


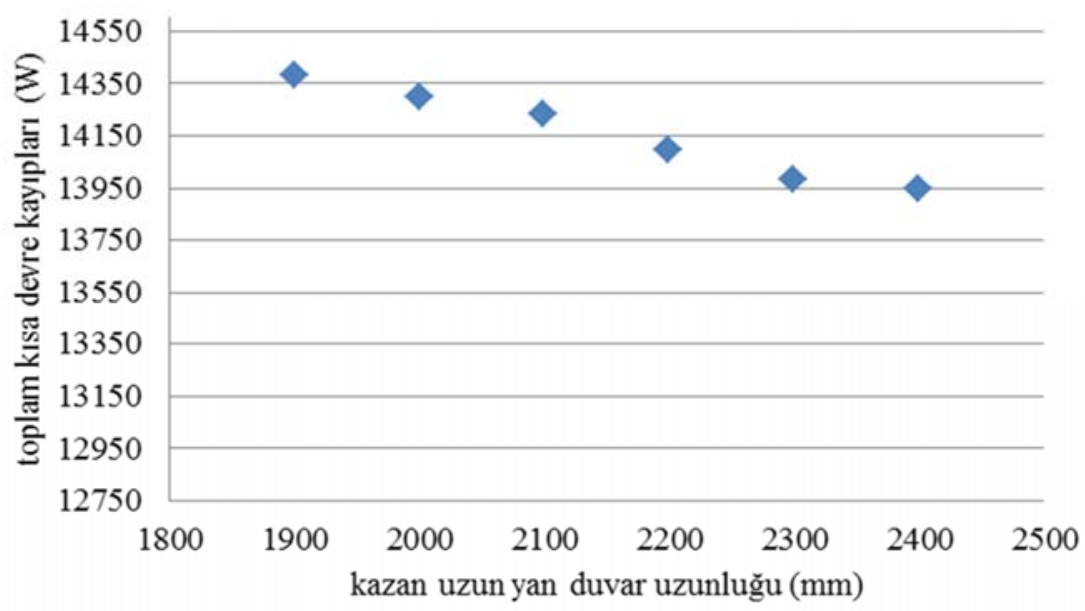

Şekil 4. Kısa devre çalışma kayıplarının kazanın uzun yan duvar uzunluğuna bağlı değişimi (Total short circuit losses of transformer vs. length of long side wall of the tank)

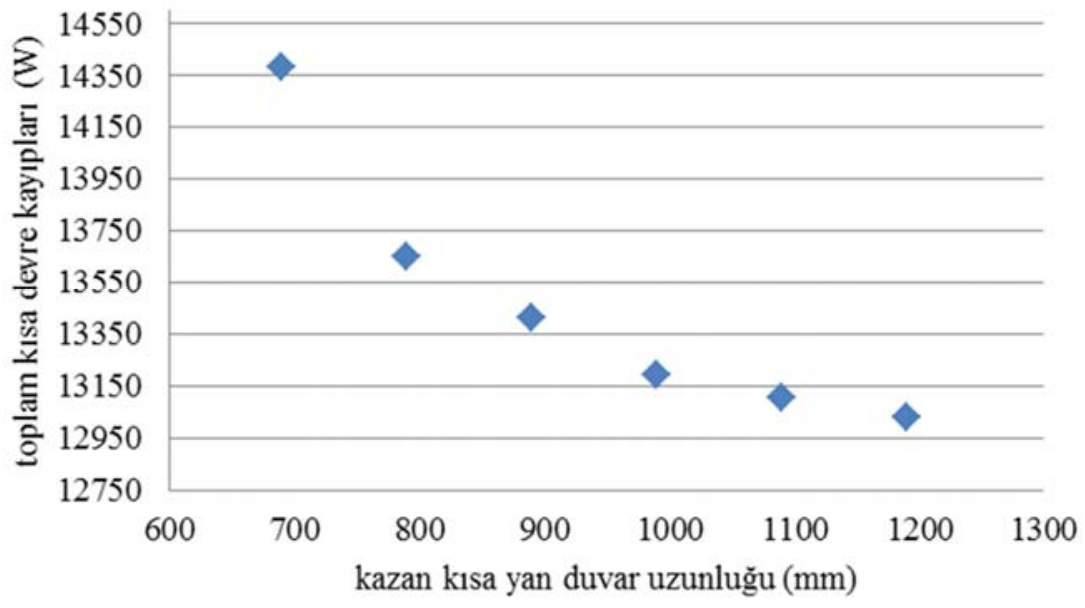

Şekil 5. Kısa devre çalışma kayıplarının kazanın kısa yan duvar uzunluğuna bağlı değişimi (Total short circuit losses of transformer vs. length of short side wall of the tank)

Kazan duvarının iç yüzeyinde meydana gelen akı yığılmaları ve bunun sonucunda ortaya çıkan güç kayıpları Şekil 3'ten görüldüğü üzere, kazan duvarının sargılar ve nüve tutucu elemanlara karşılık gelen bölgelerinde yoğunlaşmaktadır. Alüminyum ve paslanmaz çelik gibi manyetik özellikli olmayan malzemeler kullanılarak uygulanan ekranlama yönteminin etkin bir yöntem olduğu literatürde ifade edilmektedir. Bununla birlikte malzeme ve imalat maliyetleri transformatörün toplam maliyetini önemli ölçüde artırmaktadır [10]. $\mathrm{Bu}$ nedenle, transformatör nüvesinin imalatında da kullanılan M5 malzemeden imal edilen şönt elemanların kullanımı düşük maliyetli ve etkin bir yöntem olarak ön plana çıkmaktadır. Kazan duvarının iç yüzeyine yerleştirilen bu elemanlar, yüksek manyetik geçirgenlik değerleri sebebiyle kaçak akı önünde bir bariyer oluşturarak kazan duvarlarına etki etmesini engellemektedirler. Kullanılacak manyetik şönt elemanların en uygun boyutlarını ve kazan kayıpları üzerindeki etkilerini belirlemek amacıyla yoğun benzetim çalışmaları gerçekleştirilmiştir. Analizlerde kazan duvarlarının iç yüzeyine her bir uzun kazan duvarına üç adet, her bir kısa kazan duvarına da bir adet olmak üzere toplam sekiz adet şönt eleman yerleştirilmiştir. Kullanılan her bir şönt eleman, kendisine karşılık gelen sarg1 ile yatay ve dikey yönlerde simetrik olarak yerleştirilmiştir. Şönt elemanların en, boy ve kalınlıklarına bağlı olarak kazan kayıpları üzerine etkileri incelenmiştir. Elektromanyetik analizler esnasında bu üç parametreden iki tanesi sabit tutularak üçüncü parametre değiştirilmiştir. Farklı şönt eleman boyutları için yaklaşık 200 farklı analiz gerçekleştirilmiştir. Analiz sonuçları şönt eleman boyutlarına bağlı olarak Şekil 6-8'da verilmekte olup, şönt elemanların kazan duvarlarında meydana gelen kayıpları önemli miktarda azalttığı açıkça görülmektedir. İlk olarak, şönt elemanların yüksekliği $290 \mathrm{~mm}$ ile $1290 \mathrm{~mm}$ arasında $100 \mathrm{~mm}$ 'lik adımlar ile artırılarak analizler gerçekleştirilmiştir. $\mathrm{Bu}$ analizlerde her bir şönt elemanın genişliği $475 \mathrm{~mm}$, kalınlığı ise $5 \mathrm{~mm}$ değerinde sabit tutulmaktadır. 


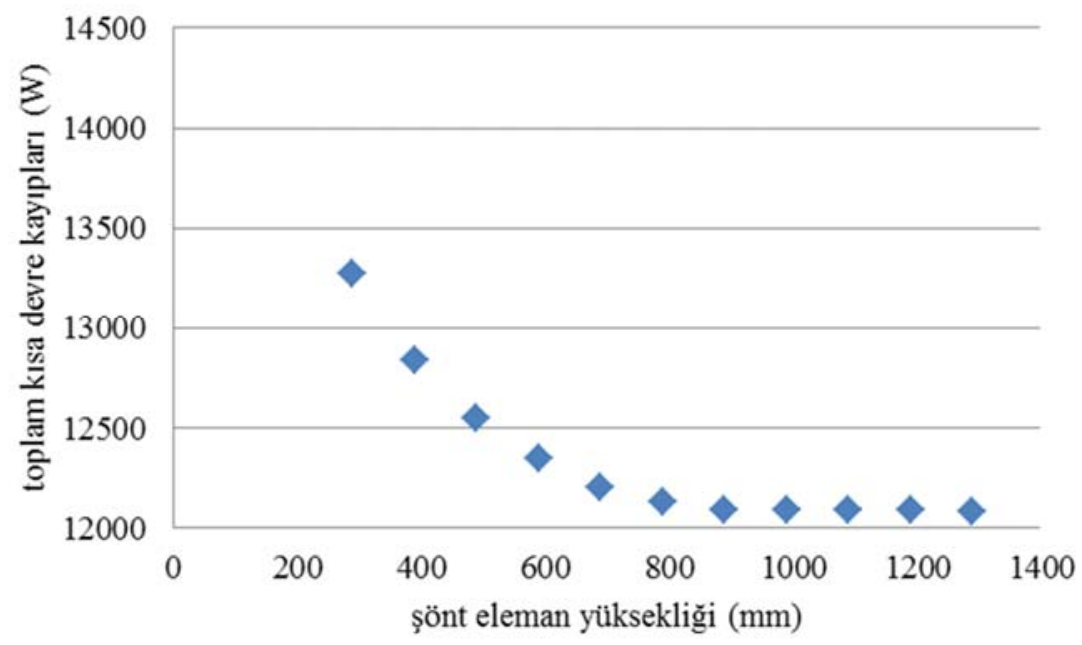

Şekil 6. Kısa devre çalışma kayıplarının şönt eleman yüksekliğine bağlı değişimi (Total short circuit losses of transformer vs. height of shunt elements)

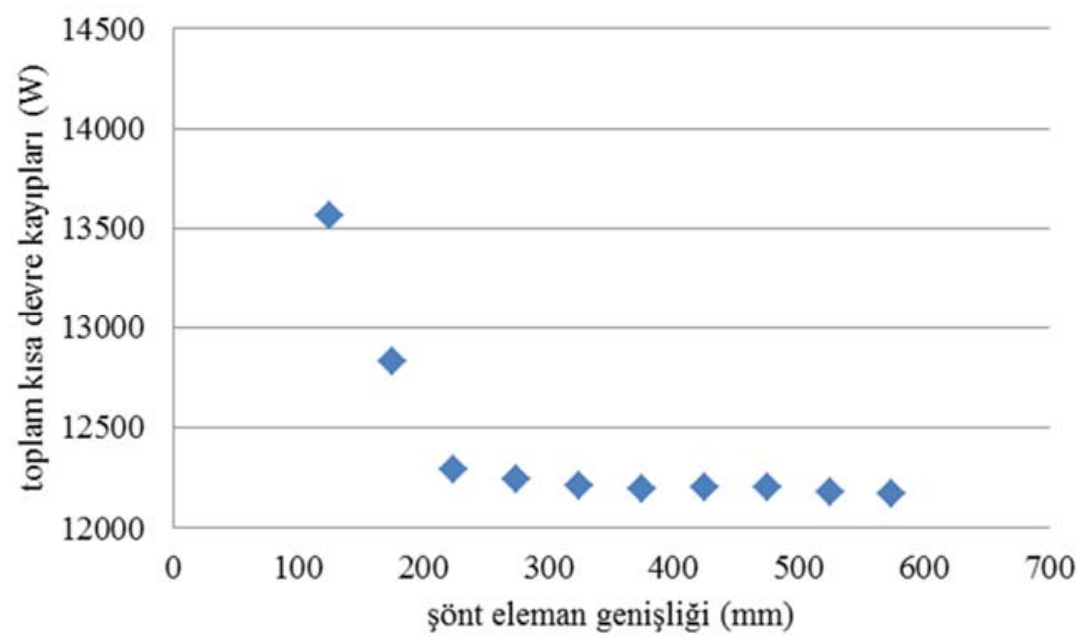

Şekil 7. Kısa devre çalışma kayıplarının şönt eleman genişliğine bağlı değişimi (Total short circuit losses of transformer vs. width of shunt elements)

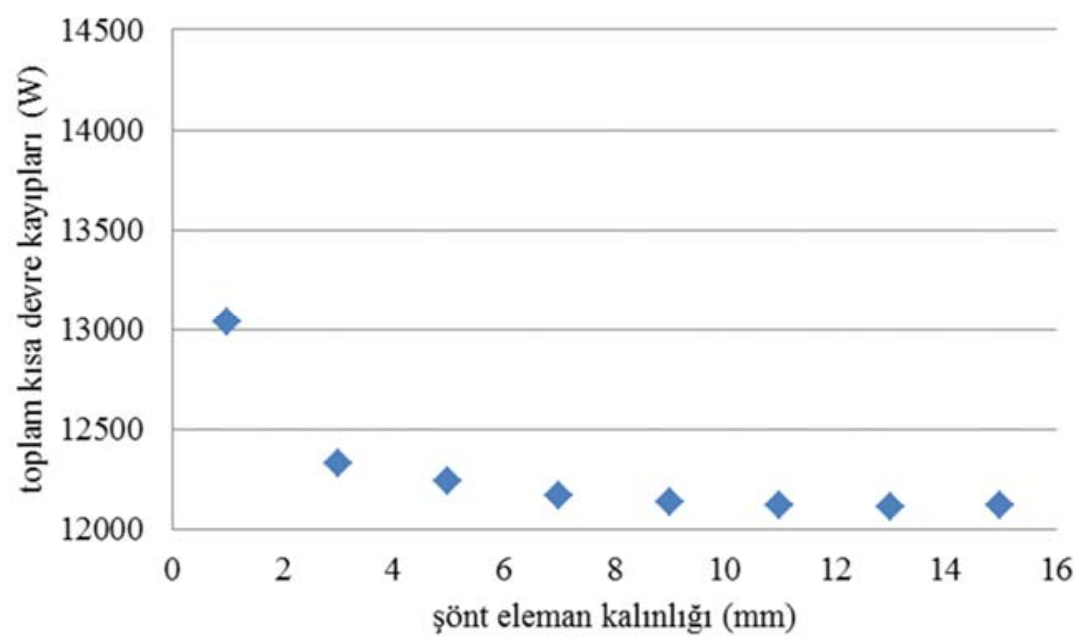

Şekil 8. Kısa devre çalışma kayıplarının şönt eleman kalınlığına bağlı değişimi (Total short circuit losses of transformer vs. thickness of shunt elements) 
290mm yükseklikteki şönt elemanın kullanıldığı durumda kazan duvarlarındaki kayıplar 1216,04W olarak hesaplanmaktadır. Yükseklik değerinin artışına bağlı olarak kazan kayıplarının azaldığı görülmekle beraber, kullanılan şönt eleman yüksekliğinin 690mm olan sargı yüksekliğini aşmasının ardından kayıplardaki azalma eğiliminin yaklaşık olarak sıfıra düştüğü gözlenmiştir. Benzer şekilde, kazan duvarlarındaki kayıpların kullanılan şönt elemanların genişliği ile ters orantılı olarak azaldığı görülmektedir. Bu azalmanın belirlenmesi için her bir manyetik şönt elemanın genişliği 50mm'lik adımlar ile $125 \mathrm{~mm}$ ile $575 \mathrm{~mm}$ arasında artırılmıştır. $\mathrm{Bu}$ analizler esnasında şönt elemanların yüksekliği bir önceki aşamada belirlenen $690 \mathrm{~mm}$ değerinde, kalınlığı ise $5 \mathrm{~mm}$ değerinde sabit tutulmaktadır. En düşük genişlik değeri olan $125 \mathrm{~mm}$ için kazan duvarlarındaki kayıplar 1506,16W olarak hesaplanmış olup, genişlik değerinin artmasıyla beraber kazan kayıpları da azalmaktadır. 275mm genişlik değerine kadar azalma eğilimi oldukça fazla olup, daha geniş ölçüler için azalma eğiliminde düşüş gözlenmektedir. Prototip transformatörün tasarım büyüklükleri göz önünde tutulduğunda, $275 \mathrm{~mm}$ 'lik genişlik değerinin yaklaşık olarak alçak gerilim sargısının dış çapına eşit olduğu görülmektedir. Son olarak ise, şönt elemanların kalınlıkları $2 \mathrm{~mm}$ 'lik adımlar ile $1 \mathrm{~mm}$ ile $15 \mathrm{~mm}$ arasında artırılarak analizler gerçekleştirilmiştir. Bu analizlerde, şönt elemanların yükseklik ve genişlik değerleri önceki analiz sonuçlarından faydalanılarak sırasıyla $690 \mathrm{~mm}$ ve $275 \mathrm{~mm}$ olarak belirlenmiştir. 1mm kalınlıktaki şönt elemanların kullanıldığı durumda kazan duvarlarında oluşan kayıpların \%38,01 oranında azaldığı, artan kalınlık değeriyle birlikte kayıpların azalmaya devam ettiği görülmektedir. $5 \mathrm{~mm}$ kalınlıktaki şönt elemanlar kazan kayıplarını \%90'dan fazla miktarda azaltmış olup, daha kalın şönt elemanların kullanımının kayıplar üzerinde önemli oranda etkisi gözlenmemiştir. Şönt elemanların kalınlıklarına yönelik analizlerde, şönt elemanlar üzerinde meydana gelen manyetik indüksiyon değerleri de izlenmiştir. 5mm kalınlık değerinden daha ince şönt elemanların kullanıldığ 1 durumlarda, şönt elemanların indüksiyon değerinin, bu elemanların imalatında kullanılan M5 malzemesinin doyma değeri olan 1,7T'lık değerin üzerinde olduğu gözlenmiştir. $\mathrm{Bu}$ aşırı değer şönt elemanlarda yüksek kayıplar meydana gelmesine ve bunun sonucunda 1sı artışına neden olacaktır. $\mathrm{Bu}$ sebeple, şönt elemanların en uygun kalınlık değerinin belirlenmesinde, transformatörde meydana gelen kaçak ak1 miktarı, sargılar ile arasındaki uzaklık, şönt elemanların üretiminde kullanılan manyetik malzemenin elektromanyetik değerleri gibi birçok parametrenin değerlendirilmesi gerektiği sonucuna varılmaktadır.

\section{KAZAN KAYIPLARININ DENEYSEL OLARAK BELİRLENMESİ (EXPERIMENTAL MEASUREMENTS OF LOSSES ON TANK WALLS)}

Önceki bölümde verilmekte olan sonuçların doğrulanması amacıyla deneysel ölçümler gerçekleştirilmiştir. Manyetik şönt elemanların üretim maliyetleri ve deneysel çalışmaların gerektirdiği zaman dikkate alınarak, analizleri hali hazırda gerçekleştirilmiş olan dört farklı şönt eleman boyutları için deneysel çalışmalar yapılmıştır. Her bir ölçüm esnasında toplam güç kayıpları, anma akım değeri kullanılarak gerçekleştirilen kısa devre çalışma testi ile belirlenmiştir. Deneysel çalışmalarda transformatör kazanının farklı kısımlarında meydana gelen kayıpların ayrı ayrı belirlenmesi mümkün olmadığından, manyetik şönt elemanların etkinliğinin belirlenmesinde kısa devre kayıp değerleri karşılaştırılarak değerlendirilmiştir. Benzer şekilde, her bir şönt eleman için benzetim çalışmalarında hesaplanmış olan toplam kısa devre kayıpları deneysel ölçümlerde elde edilen değerler ile karşılaştırılmıştır. Kullanılan şönt eleman boyutları ile kısa devre kayıplarının hesaplanan ve ölçülen değerleri Tablo 2'de verilmektedir. Bir ve dört numaralı testlerde kullanılan şönt elemanların kazan duvarları içerisine yerleştirildiği durumlar Şekil 9 ve Şekil 10'da gösterilmektedir.

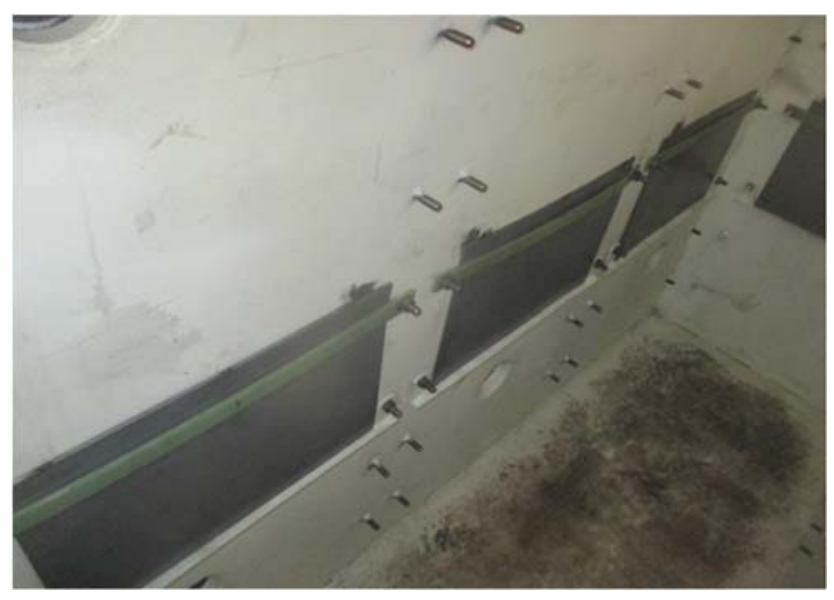

Şekil 9. Test-1'de kullanılan şönt elemanların kazan içerisindeki yerleşimi

(View of shunt packages, arranged in Test-1)

Tablo 2. Farklı şönt uygulamaları için elde edilen kısa devre kayıplarının karşılaştırılması (Comparison of short circuit losses for experimented shunt applications)

\begin{tabular}{lllllll}
\hline \multirow{2}{*}{$\begin{array}{l}\text { Test } \\
\text { no }\end{array}$} & \multicolumn{4}{l}{ Şönt eleman boyutları, mm } & \multicolumn{3}{l}{ Kisa devre kayıları, W } & \multirow{2}{*}{ Yükseklik } & Genişlik & Kalınlık & Hesaplanan & Ölçülen & Hata \\
\hline 1 & 290 & 475 & 5 & 13268,43 & 12670 & $-4,7$ \\
2 & 690 & 475 & 5 & 12203,18 & 12040 & $-1,36$ \\
3 & 690 & 275 & 5 & 12237,61 & 12161 & $-0,63$ \\
4 & 690 & 475 & 13 & 12102,71 & 11890 & $-1,79$ \\
\hline
\end{tabular}




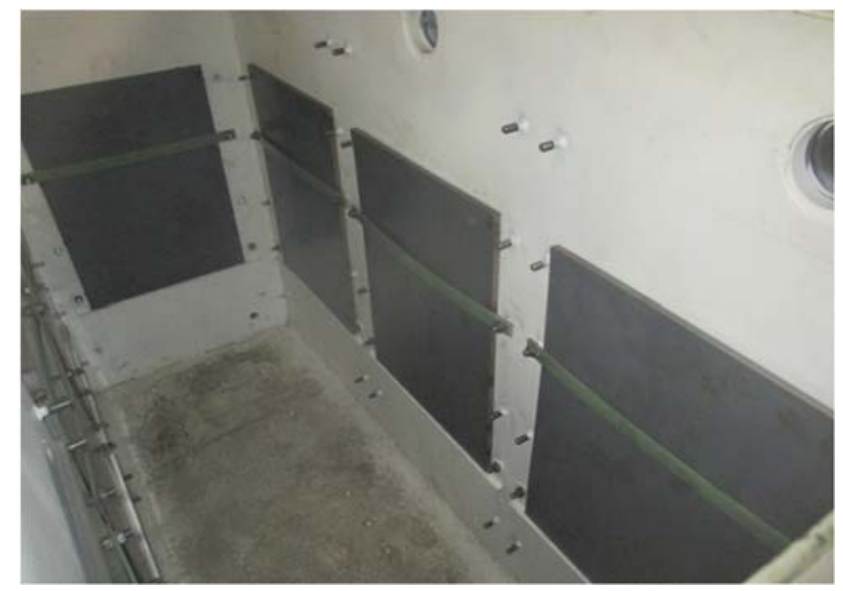

Şekil 10. Test-1'de kullanılan şönt elemanların kazan içerisindeki yerleşimi

(View of shunt packages, arranged in Test-4)

Her bir test için elde edilmiş olan ölçüm değerlerinin oldukça yüksek doğruluk oranı ile benzetim çalışması sonuçlarını doğruladığı görülmektedir. Buradan yola çıkarak, deneysel olarak doğrulanmamış olan benzetim çalışmalarının sonuçlarının da benzer şekilde yüksek doğrulukta olduğu öngörülmektedir. Sonuçlar değerlendirildiğinde, kazan duvarlarının iç yüzeylerine yerleştirilen şönt elemanlar ile transformatörün kısa devre kayıplarında yaklaşık \%16'ya kadar azalma sağlandığı görülmektedir. Bu değer, yaklaşık olarak kaçak akıların kazan duvarlarında meydana getirdiği kazan kayıplarının tamamına karşılık gelmektedir. Belirlenmiş olan en uygun boyutlardaki şönt elemanların kullanımı ile azaltılan kazan kayıpları, hesaplanan toplam kazan kayıplarının \%91,43'üne karş1lık gelmekte olup, bu değerin transformatörün kısa devre kayıplarının ise \%14,9'una eşit olduğu hesaplanmaktadır. Buradan yola çıkarak, önerilen en uygun boyutların oldukça tatminkar sonuçlar verdiği belirlenmektedir. Önerilen boyutlardaki her bir şönt elemanın ağırlığ1 7,26kg olup, kullanılan sekiz adet şönt elemanın toplam ağırlığ $158,06 \mathrm{~kg}$ 'dır. Bu değer, Bölüm 4'te verilmiş olan kazan boyutlarının artışı ile ortaya çıkan ağırlık değeri ile kıyaslandığında oldukça düşüktür. Kayıp değerinde sağlanan azalma oranı ile birlikte değerlendirildiğinde, şönt elemanlar kullanarak kayıpları azaltmanın üstünlüğü açıkça görülmektedir.

\section{SONUÇLAR (CONCLUSIONS)}

$\mathrm{Bu}$ çalışmada, bir transformatörün kazan duvarlarında meydana gelen kayıpların azaltılması amaciyla en uygun boyutlardaki şönt elemanların belirlenmesi hedeflenmektedir. Çalışmalar, bu amaçla özel olarak tasarlanmış olan $1000 \mathrm{kVA}$ gücündeki bir dağıtım transformatörü kullanılarak gerçekleştirilmiştir. Üç boyutlu sonlu elemanlar yönteminden faydalanılarak gerçekleştirilmiş olan analiz sonuçları deneysel çalışmalar ile doğrulanmıştır. Kazan kayıplarını meydana getiren başlıca faktörün transformatördeki kaçak akılar olması sebebiyle, kazan duvarlarındaki kayıpları tatmin edici ölçüde azaltılmasını sağlayacak en uygun şönt eleman boyutları, transformatörün sargılarının ve nüvenin tasarım boyutlarına bağl1 olarak ifade edilmiştir. Buna göre, kullanılacak şönt elemanların genişliğinin alçak gerilim sargısının dış çap değerinden küçük, yüksek gerilim sargısının iç çap değerinden ise daha geniş seçilmemesinin uygun olacağ görülmektedir. Benzer şekilde şönt elemanların yüksekliğinin sargıların yükseklik değerinden küçük, nüve penceresinin yüksekliğinden ise daha büyük olmaması kazan kayıplarının tatmin edici düzeyde azaltılması için yeterli olmaktadır. Şönt elemanların kalınlığı belirlenmesi esnasında ise malzemenin BH eğrisi dikkate alınmalı ve kaçak akının şönt elemanlar üzerinde doymaya neden olmayacağı kalınlık değeri belirlenmesi gerekmektedir. Çalışmada, bu şekilde belirlenmiş olan şönt eleman boyutları ile kazan duvarlarındaki kayıpların \%91,43 oranında azaltılması sağlanmıştır. Bu değer transformatörün toplam kısa devre kayıplarının \%14,9'una karşılık gelmektedir. Ek olarak, şönt elemanların nüve üretiminde de kullanılmakta olan manyetik malzeme kullanılarak imal edilmesinin, transformatörün toplam maliyetinin en düşük düzeyde artması yönünden de üstünlük sağladığı görülmektedir.

\section{TEŞEKKÜR (ACKNOWLEDGEMENT)}

Bu çalışma, TÜBİTAK tarafından desteklenen 7140894 no'lu Bilimsel Araştırma Projesi kapsamında gerçekleştirilmiştir. Prototip transformatörün imalatında ve deneysel çalışmalarda Sönmez Transformatör San. ve Tic. A.Ş. tarafından sağlanan imkânlar kullanılmıştır.

\section{KAYNAKLAR (REFERENCES)}

1. EN 50588-1, Medium power transformers $50 \mathrm{~Hz}$, with highest voltage for equipment not exceeding $36 \mathrm{kV}-$ Part 1: General requirements, June 2015.

2. Scholand M., Blackburn T., Hopkinson P., Sampat M., SEAD Distribution Transformers Report Part 3: Energy Efficiency Class Definitions, The Super-efficient Equipment and Appliance Deployment, Canada, 11-13, 2013.

3. Vogel F.J., Adolphson E.J., A Stray Loss Problem in Transformer Tanks, Transactions of the American Institute of Electrical Engineers (Trans. Am. Inst. Electr. Eng.), 73 (1), 760-764, 1954.

4. Venegas Vega M.A., Escarela Perez R., Niewierowicz T., 3D Finite Element Estimation of Stray Losses in Three-Phase Transformers, Journal of Applied Computer Science, 16 (1), 89-99, 2008.

5. Schmidt E., Hamberger P., Seitlinger W., Finite Element Calculation of Eddy Current Losses in the Tank Wall of Power Transformers, IEEE International Electric Machines and Drives Conference, Wisconsin-USA, 1167-1173, 1-4 June, 2003.

6. Adalja C.C., Jain M.L., Analysis of Stray Losses in Power Transformers by 3-D Magnetic Field Simulation, Fifteenth National Power Systems Conference, Mumbai-India, 498-503, 16-18 December, 2008.

7. Susnjic L., Haznadar Z., Valkovic Z., 3D finite-element determination of stray losses in power transformer, 
Electric Power Systems Research (Electr. Power Syst. Res.), 78, 1814-1818, 2008.

8. Susnjic L., Haznadar Z., Valkovic Z., Electromagnetic Analysis Applied to the Prediction of Stray Losses in Power Transformer, International Conference on Electrical Machines, Cracow-Poland, 907-908, 5-8 September, 2004.

9. Kirar M., Gupta G., Kumar M., Sharma V.K., Study of Stray Losses Reduction through Finite Element Method, Annual IEEE India Conference, Mumbai-India, 1-5, 1315 December, 2013.

10. Olivares J.C., Canedo J., Moreno P., Driesen J., Escarela R., Palanivasagam S., Experimental study to reduce the distribution-transformers stray losses using electromagnetic shields, Electric Power System Research (Electr. Power Syst. Res.), 63, 2002.

11. Milagre A.M., Ferreira da Luz M.V., Cangane G.M., Komar A., Avelino P.A., 3D Calculation and Modeling of Eddy Current Losses in a Large Power Transformer, International Conference on Electrical Machines, Sapporo-Japan, 2282-2286, 21-24 October, 2012.

12. Magdaleno-Adame S., Olivares-Galvan J.C., Escarela R., Raichenko O., Kladas A.G., Hot Spots Mitigation on Tank Wall of a Power Transformer using Electromagnetic Shields, International Conference on Electrical Machines, Berlin-Germany, 2235-2238, 2-5 September, 2014.
13. Mokkapaty S.P.K., Weiss J., Schramm A., MagdalenoAdame S., Schwarz H., Olivares-Galvan J.C., 3D Finite Element Analysis of Magnetic Shunts and Aluminum Shields in Clamping Frames of Distribution Transformers, IEEE International Autumn Meeting on Power, Electronics and Computing, Ixtapa-Mexico, 1-6, 4-6 November, 2015.

14. Li L., Fu W.N., Ho S.L., Niu S., Li Y., Numerical Analysis and Optimization of Lobe-Type Magnetic Shielding in a 334 MVA Single-Phase AutoTransformer, IEEE Transactions on Magnetics (IEEE Trans. Magn), 50 (11), 2014.

15. Kumbhar G.B.S., Mahajan M., Collett W.L., Reduction of Loss and Local Overheating in the Tank of a Current Transformer, IEEE Transactions on Power Delivery (IEEE Trans. Power Delivery), 25 (4), 2519-2525, 2010.

16. Valkovic Z., Some Aspects of Stray Losses in Large Power Transformers, Applied Electromagnetics, 36 (25), 238-243, 2002.

17. ANSYS Inc., ANSYS Maxwell 3D User's Guide, Canonsburg, PA, USA 2010.

18. Kralj L., Miljavec D., Stray losses in power transformer tank walls and construction parts, XIX International Conference on Electrical Machines, Rome-Italy, 1-4, 68 September, 2010. 